\title{
Risk factors of postpartum depression and depressive symptoms: umbrella review of current evidence from systematic reviews and meta-analyses of observational studies
}

\author{
Chiara Gastaldon, Marco Solmi, Christoph U. Correll, Corrado Barbui and Georgios Schoretsanitis
}

\section{Background}

Evidence on risk factors for postpartum depression (PPD) are fragmented and inconsistent.

\section{Aims \\ To assess the strength and credibility of evidence on risk factors of PPD, ranking them based on the umbrella review methodology.}

\section{Method}

Databases were searched until 1 December 2020, for systematic reviews and meta-analyses of observational studies. Two reviewers assessed quality, credibility of associations according to umbrella review criteria (URC) and evidence certainty according to Grading of Recommendations-AssessmentDevelopment-Evaluations criteria.

\section{Results}

Including 185 observational studies $(n=3272093)$ from 11 systematic reviews, the association between premenstrual syndrome and PPD was the strongest (highly suggestive: odds ratio $2.20,95 \% \mathrm{Cl} 1.81-2.68$ ), followed by violent experiences (highly suggestive: odds ratio $(\mathrm{OR})=2.07,95 \% \mathrm{Cl} 1.70-2.50$ ) and unintended pregnancy (highly suggestive: $\mathrm{OR}=1.53,95 \% \mathrm{Cl} 1.35-1.75$ ). Following URC, the association was suggestive for Caesarean section $(\mathrm{OR}=1.29,95 \% \mathrm{Cl} 1.17-1.43)$, gestational diabetes $(\mathrm{OR}=$ $1.60,95 \% \mathrm{Cl} 1.25-2.06)$ and 5 -HTTPRL polymorphism (OR $=0.70$, $95 \% \mathrm{Cl} 0.57-0.86)$; and weak for preterm delivery $(\mathrm{OR}=2.12,95 \%$
$\mathrm{Cl} 1.43-3.14)$, anaemia during pregnancy $(\mathrm{OR}=1.47,95 \% \mathrm{Cl} 1.17-$ 1.84), vitamin $\mathrm{D}$ deficiency $(\mathrm{OR}=3.67,95 \% \mathrm{Cl} 1.72-7.85)$ and postpartum anaemia (OR $=1.75,95 \% \mathrm{Cl} 1.18-2.60)$. No significant associations were found for medically assisted conception and intra-labour epidural analgesia. No association was rated as 'convincing evidence'. According to GRADE, the certainty of the evidence was low for Caesarean section, preterm delivery, 5-HTTLPR polymorphism and anaemia during pregnancy, and 'very low' for remaining factors.

\section{Conclusions}

The most robust risk factors of PDD were premenstrual syndrome, violent experiences and unintended pregnancy. These results should be integrated in clinical algorithms to assess the risk of PPD.

\section{Keywords}

Depressive disorders; perinatal psychiatry; umbrella review; risk factors; postpartum depression.

\section{Copyright and usage}

(c) The Author(s), 2022. Published by Cambridge University Press. This is an Open Access article, distributed under the terms of the Creative Commons Attribution licence (https://creativecommons.org/licenses/by/4.0/), which permits unrestricted re-use, distribution, and reproduction in any medium, provided the original work is properly cited.
Postpartum depression (PPD) is a disorder characterised by symptoms of major depression occurring after delivery. ${ }^{1}$ The DSM-5 uses a peripartum specifier for affective symptoms occurring within 4 weeks after childbirth, ${ }^{2}$ but longer time frames of up to 1 year postpartum are also used in clinical and research settings. ${ }^{3-5}$ This differentiation in terms of onset timing may account for the considerable phenomenological heterogeneity of PPD, which is increasingly gaining attention. ${ }^{6}$ Additionally prevalence rates of PPD vary worldwide with estimates ranging between 10 and $25 \%{ }^{1}$ These rates suggest that an epidemiologically relevant proportion of women in the peripartum phase suffer from PPD. Therefore, PPD introduces globally a major public health problem with adverse sequelae for maternal and offspring well-being. ${ }^{7-9}$ Specifically, PPD has been associated with maternal and familiar distress, ${ }^{1}$ suicidal risk, impaired child development and behaviour outcomes. ${ }^{9,10}$ Awareness regarding screening, detecting and treating PPD has increased in past years. ${ }^{11,12}$ Nevertheless, the understanding of related mechanisms and associated risk factors remains poor. ${ }^{1,3}$ Across risk factors of PPD, research has yielded evidence for several predictors. A substantial body of literature has contributed data on various types of PPD risk factors mainly using casecontrol and cohort design studies, ${ }^{13}$ which are the most appropriate type of study to answer such epidemiological questions. ${ }^{14}$ History of affective disorders and life stress are among the early identified major risk factors for PPD. ${ }^{15}$ Moreover, consistent data suggests higher risk of PPD in women having experienced violence. ${ }^{16,17}$ Different types of violence, such as child and adult physical, sexual and psychological abuse, have been strongly associated with PPD symptoms. ${ }^{1}$ Further, lower socioeconomic status and social resources have been also investigated in the context of PPD, implying a clear role for lack of social support when facing obstetrical complications. ${ }^{18,19}$ The effects of complications during pregnancy and delivery have been addressed in an interdisciplinary fashion. Specifically, the effects of conditions such as gestational diabetes (GDM), preeclampsia, vitamin D deficiency and anaemia, as well as exercise and dietary habits, on the prevalence of affective symptoms in the peripartum have been investigated. ${ }^{20-24}$ Parallel to complications during pregnancy, aggravating or protective factors related to delivery, such as preterm birth, use of labour analgesia and Caesarean section, have also been assessed. ${ }^{25-27}$ Although data are increasingly available, methodological controversies introduce limited generalisability, and hamper a global understanding of risk factors and a pragmatic risk quantification. ${ }^{13,28}$ Moreover, as quality indicators directly affect the certainty of risk estimates, 
formal syntheses of the credibility of the exponentially emerging fragmented meta-analyses are required. ${ }^{28}$ This umbrella review aimed to identify, quantify and measure the degree of credibility of the association of PPD with different risk factors, including peripheral markers, obstetric complications and psychological factors.

\section{Method}

We used the Meta-analysis of Observational Studies in Epidemiology (MOOSE) guidelines to guide this umbrella review (Supplementary Table 1, available at https://doi.org/10.1192/bjp. 2021.222). ${ }^{29}$

The review protocol was registered with International Prospective Register of Systematic Reviews (PROSPERO; registration number CRD42020168468).

\section{Study design}

We summarised the evidence from multiple research syntheses, performing an umbrella review, ${ }^{28}$ which is a form of review of previously conducted systematic reviews and meta-analyses. It consists in repeating the meta-analyses adopting a uniform approach for available factors to enable their comparison. ${ }^{30}$ Considering the growing number of systematic reviews and meta-analyses available, this approach allows us to compare and contrast the findings of separate reviews related to a topic of interest. ${ }^{31}$ The conduct of an umbrella review also provides a comprehensive overview of healthcare areas, to highlight whether the evidence is consistent or contradictory, and to explore possible heterogeneity sources for existing evidence. ${ }^{31,32}$ This type of review is considered among the highest level of evidence, ${ }^{33}$ and is particularly useful to inform clinical practice and policies. ${ }^{34}$ Further details are described in the Supplementary Methods.

Two reviewers (C.G. and G.S.) independently conducted the literature search; the screening of the titles, abstracts and full-text papers; and the data extraction. Details of the process are described in the Supplementary Methods.

Eligible reviews were exclusively systematic reviews with a meta-analysis. We considered systematic reviews of observational studies (prospective or retrospective cohort and case-control studies) that investigated the association between exposure to any risk factor and the risk of developing PPD. We excluded systematic reviews that did not present study-level data, such as odds ratios or relative risks with $95 \%$ confidence intervals. When more metaanalyses on the same research topic were available, the metaanalysis with the largest number of included studies, providing effect sizes at a study level, was considered for inclusion, as previously described. ${ }^{35-37}$ From each included systematic review, two investigators (C.G. and G.S.) independently extracted information on first author, publication year, outcomes of interest, number of studies per meta-analysis and summary meta-analytic estimates. Primary studies included in all systematic reviews were retrieved and inspected by two reviewers (C.G. and G.S.). Details of the selection and extraction process are described in the Supplementary Methods.

\section{Reporting quality of included systematic reviews and meta-analyses}

Two reviewers (C.G. and G.S.) independently assessed the quality of each systematic review, using A Measurement Tool to Assess Systematic Reviews (AMSTAR-2), a 16-point assessment tool of the methodological quality of systematic reviews. AMSTAR-2 has good interrater agreement, test-retest reliability and content validity (details in the Supplementary Methods). ${ }^{38}$
It assesses the methodological strength of reviews, through 16 domains, which include the research question and design, literature search, data extraction, explicit reports of each step and choice made by reviewers to allow transparency (e.g. presence of a list of excluded studies, with reason for exclusion), quality and statistical assessments. Each item allows for the following response options: yes, partial yes or no. Of these 16 domains, seven are considered critical domains, as they can particularly affect the validity of the review and its conclusion. The AMSTAR-2 is a qualitative tool, not designed to be scored. AMSTAR-2 offers a scheme for interpreting weaknesses identified in critical and non-critical items: reviews with no or only one non-critical weakness are considered 'high quality'; reviews with more than one non-critical weakness but no critical flaws are considered 'moderate quality'; reviews with only one critical flaw with or without non-critical weaknesses are considered 'low quality'; finally, reviews with more than one critical flaw with or without non-critical weaknesses are considered 'critically low quality' (see Supplementary Methods and Supplementary Box 1 for further details). ${ }^{38,39}$

\section{Statistical analysis and umbrella review criteria}

We extracted effect sizes of individual studies included in each meta-analysis for every association, and afterwards we re-estimated the summary effect sizes with $95 \%$ confidence intervals, using random-effects models as we expected large heterogeneity. ${ }^{40}$ Additionally, we calculated the $95 \%$ prediction intervals for the summary random effect sizes, which account for heterogeneity between studies and specify the uncertainty for the effect that would be expected in a new study examining that same research question. ${ }^{41}$ We evaluated heterogeneity with Cochran's Q-statistic (statistical significance set at $P$-value $<0.10)$ and estimated with the $I^{2}$ metric. $^{42}$ The $I^{2}$ ranges from 0 to $100 \%$, and it is considered very large, large, moderate and low for values $\geq 75 \%, 50-74 \%, 25-49 \%$ and $<25 \%$, respectively. ${ }^{43}$ Potential publication and small-study effects biases were evaluated with Egger's test. ${ }^{44,45}$ Specifically, small-study effects bias was considered to be present when a more conservative effect in the largest study and a $P$-value $\leq 0.10$ in the regression asymmetry test were found. Further, we assessed the excess significance, which is a test that examines if the observed number of studies $(O)$ with statistically significant results (i.e. with $P<0.05)$ in the meta-analysis is higher than the expected number (E). ${ }^{46}$ For each meta-analysis, $E$ was calculated as the sum of the statistical power estimates for every study in the meta-analysis. The power of each study was calculated assuming a non-central $t$ distribution. ${ }^{47}$ The estimated power depends on the plausible effect size. As the true effect size for any meta-analysis is unknown, this approach assumes that the most plausible effect is the one provided by the largest study included. Excess significance for all meta-analyses was set at $P$-value $\leq 0.10 .^{35,46,48,49}$ Statistical analyses were performed with RSTUDIO version 1.3.1056 for Windows (RStudio, Boston MA, US; see https://www.rstudio.com/products/rstudio/download/).

Based on the above calculations, we assessed the umbrella review criteria (URC) to classify the strength of associations as 'convincing' (class I), 'highly suggestive' (class II), 'suggestive' (class III) or 'weak' (class IV) (details in Supplementary Box 2). ${ }^{28,50-55}$ Precisely, meta-analyses were considered without bias (class I) if they met the following criteria: $\geq 1000$ cases, random-effects $P$ value $\leq 10^{-6}$ of the meta-analysis, low or moderate between-study heterogeneity $\left(I^{2} \leq 50 \%\right), 95 \%$ prediction intervals that excluded the null value, and absence of both small-study effects and excess significance. Associations were considered highly suggestive (class II) when the following criteria were met: $\geq 1000$ cases, highly significant summary associations ( $P$-value $\leq 10^{-6}$ in the random-effects estimate) and $95 \%$ prediction intervals not including the null 
value. Suggestive evidence (class III) criteria required $\geq 1000$ cases and $P$-value $\leq 0.001$ in the random-effects model. Weak association (class IV) criteria required only $P$-value $\leq 0.05$. Associations were not considered significant if the $P$-value in the random-effects model was $\geq 0.05$. All $P$-values were two tailed.

\section{Grading of Recommendations, Assessment, Development and Evaluations}

Additionally, the overall certainty in the estimates was qualitatively assessed by two reviewers (G.S. and C.G.) - with one author (C.B.) adjudicating the decision in case of discrepancies - using the Grading of Recommendations, Assessment, Development and Evaluations (GRADE) method. ${ }^{56}$

GRADE allows to rate the certainty of estimate for each outcome and gives an overview of findings easily understandable for patients, clinicians, researchers, guideline developers and policy makers. ${ }^{57}$ The following factors were considered for each outcome of interest, according to the GRADE method: study design, risk of bias, inconsistency, imprecision, indirectness, presence of large effect, dose-response gradient and publication bias. ${ }^{45}$

Based on GRADE assessments, the certainty of estimates was classified as high, moderate, low or very low (further details in Supplementary Box 3). ${ }^{58}$ In the case of observational studies, the certainty of evidence is low when there are no reasons to downgrade the certainty of evidence, and very low when at least one reason to downgrade the certainty of evidence is found. The only case in which evidence from observational studies could be 'moderate' is when some reason to upgrade the certainty of evidence is found (e.g. strong association), with no downgrades on the other items.

Tables of summary of findings were developed with the GRADEProGDT app (GRADEpro Guideline Development Tool [Software], McMaster University and Evidence Prime, Canada; see gradepro.org).

\section{Overall evaluation}

Risk factors were quantified together with a formal assessment of the certainty of estimates, using quantitative URC and GRADE. We employed both methods because they are complementary. The URC quantitatively evaluate the strength of the associations, and GRADE qualitatively assesses the certainty of evidence. We ranked all risk factors based first on the strength of each association (URC), then on the certainty of evidence (GRADE), and finally, on the quality of the systematic review (AMSTAR-2).

\section{Sensitivity analyses}

We performed three sensitivity analyses to assess whether the credibility of the evidence and the strength of the association varied when the following studies were retained in the analysis: cohort studies; studies in which the PPD diagnosis/symptoms were assessed with standardised criteria (e.g. ICD or DSM diagnosis, The MiniInternational Neuropsychiatric Interview (M.I.N.I.), Structured Clinical Interview for DSM Disorders (SCID) or Edinburgh Postnatal Depression Scale (EPDS) score with a cut-off score of $\geq 13$ ), excluding non-validated or self-assessed screening tools; and studies assessing mood symptoms at least 7 days after delivery (further details in Supplementary Methods).

\section{Results}

\section{Description of studies included in the meta-analyses}

The systematic search yielded 703 records. After duplicate removal, title and abstract screening, 73 full-text articles were retrieved and checked for inclusion. Eleven systematic reviews were included, including 12 meta-analyses, with 185 primary studies and 3272093 participants (Fig. 1 and Supplementary Table 2). The excluded articles and the reasons for their exclusion are provided in the Supplementary Material.

The 12 risk factors reported in the 11 systematic reviews were anaemia (during pregnancy and postpartum), GDM, Caesarean section, preterm delivery, intra-labour epidural analgesia, medically assisted conception, violent experiences, premenstrual syndrome (PMS), vitamin D deficiency and unintended pregnancy, whereas one review provided data on a protective factor, the presence of the serotonin-transporter-linked polymorphic region (5-HTTLPR) polymorphism. Supplementary Table 2 summarises the main review and individual study characteristics. The number of studies per meta-analysis ranged between 4 and 33. Seven meta-analyses included $\geq 1000$ cases (range 1074-15758), and five had $<1000$ cases. Of the 185 studies, 123 (66.5\%) were cohort studies and 62 (33.5\%) adopted a case-control or cross-sectional design. Study participants were pregnant females, exposed to one or multiple risk factors. PPD was identified with an EPDS score of $\geq 13$ or with ICD-9 or 10 or DSM-IV criteria in 81 studies; the remaining studies used self-reported or other scales or operational criteria. Assessments of mood symptoms were conducted within the first postpartum week in 31 studies.

\section{Quality assessment of the systematic reviews}

The PMS review was of moderate quality according to the AMSTAR-2 scoring system, ${ }^{59}$ the systematic review on medically assisted conception was of low quality, ${ }^{60}$ and the remaining nine were of critically low quality (Table 1). ${ }^{17,21,25-27,61-64}$ The most common weakness was that all the systematic reviews did not contain an explicit statement that the review methods were established before the conduct of the review (Table 1, question 2), with the exception of the review on preterm delivery. ${ }^{25}$ The nine reviews rated as critically low also did not provide a list of excluded studies with reasons to justify the exclusion (Table 1, question 7). ${ }^{17,21,25-27,61-64}$ Other critical flaws were that authors did not consider the risk of bias when interpreting results (Table 1, question 13), and the absence of adequate investigation of publication bias or small study bias and their impact on the results (Table 1, question 15).

\section{Summary of associations and URC}

Ten meta-analyses showed significant summary random-effects estimates; exposure to PMS, violent experiences, unintended pregnancy, Caesarean section, preterm delivery, GDM, anaemia during pregnancy, vitamin $\mathrm{D}$ deficiency and postpartum anaemia increased the risk of PPD (Table 2 and Fig. 2). ${ }^{17,21,23,25,26,59,61-63}$ Conversely, the 5-HTTLPR polymorphism was associated with a lower PPD risk. ${ }^{64}$ Associations between PPD and medically assisted conception or intra-labour analgesia were not significant. ${ }^{27,60}$

According to the URC, three associations (between PPD and PMS, violent experiences and unintended pregnancy) were highly suggestive (class II); three associations (between PPD and Caesarean section, GDM and 5-HTTLPR polymorphism) were suggestive (class III); four associations (between PPD and preterm delivery, anaemia during pregnancy, vitamin $\mathrm{D}$ deficiency and postpartum anaemia) were weak (Table 2); and non-significant associations were reported for medically assisted conception and labour epidural analgesia.

\section{Certainty of evidence according to GRADE}

For Caesarean section, preterm delivery, anaemia during pregnancy and 5-HTTLPR polymorphism, the certainty was rated as low 


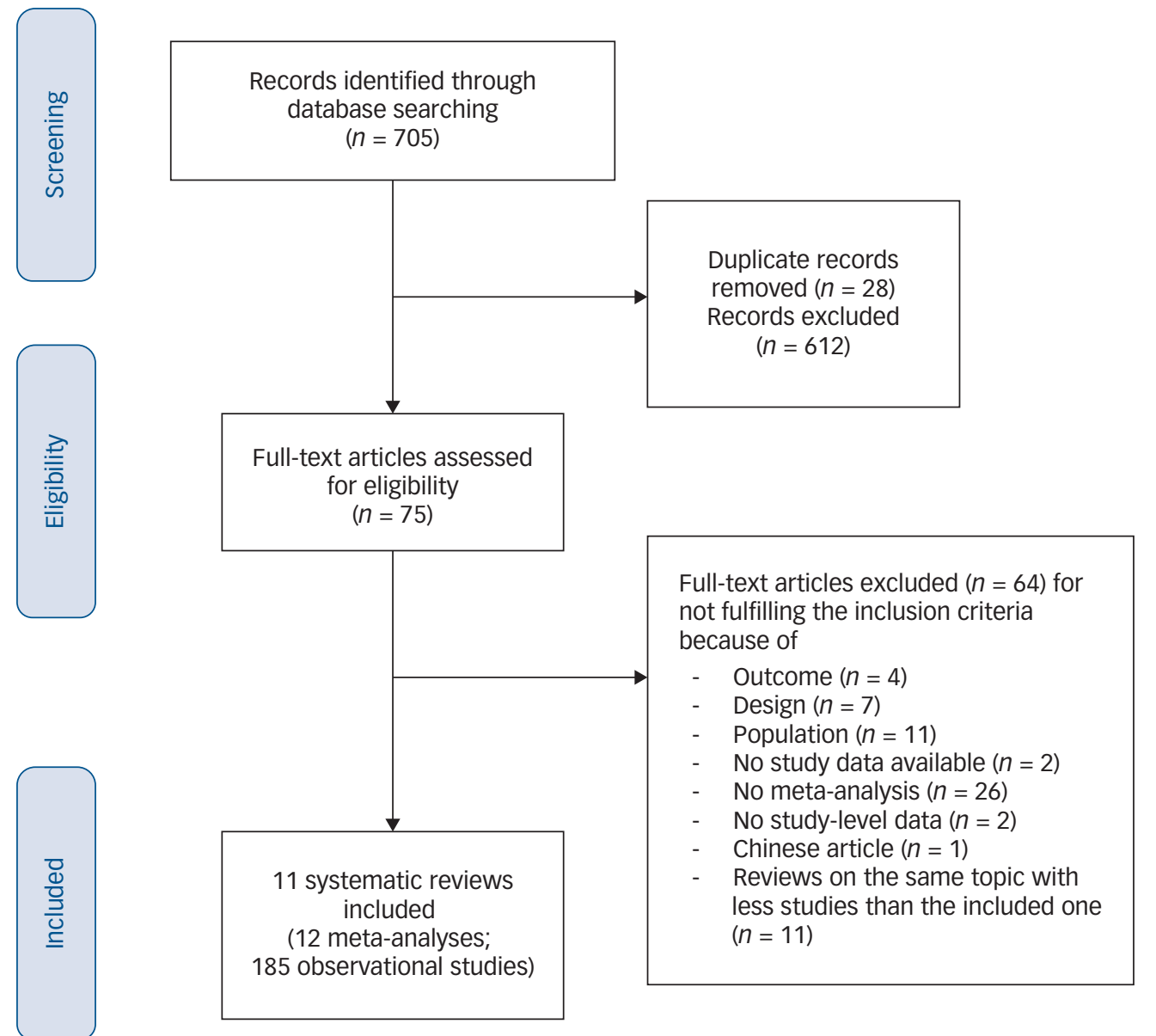

Fig. 1 PRISMA flow chart. Flow chart of included and excluded systematic reviews and meta-analyses.

(Table 3), based on the a priori GRADE baseline assumption of low certainty for observational studies. We found no reasons to upgrade this baseline evaluation. For postpartum anaemia, PMS, violent experiences, GDM, labour epidural analgesia and unintended pregnancy, the certainty was very low, mainly because of inconsistency.

\section{Overall ranking}

Figure 2 presents a ranking of associations based on URC, GRADE and AMSTAR-2. The association between PPD and PMS was the most reliable, followed by associations with violent experiences and unintended pregnancy. The association with Caesarean section, GDM and 5-HTTLPR was suggestive, and the association with preterm delivery, anaemia during pregnancy, vitamin $\mathrm{D}$ deficiency and postpartum anaemia was weak. No association was found for medically assisted conception or intra-labour epidural analgesia.

\section{Sensitivity analyses}

In cohort studies, the associations between PPD and violent experiences (class II), unintended pregnancy (class II), GDM (class III), preterm delivery (weak), vitamin D deficiency (weak), postpartum anaemia (weak), medically assisted conception (no association) and intra-labour analgesia (no association) remained at the same strength. Conversely, the association with PMS was downgraded from highly suggestive (class II) to weak because the criterion of $\geq 1000$ cases was not met. Moreover, for PMS, the GRADE certainty assessed in the sensitivity analysis was in contrast with the URC, as it was upgraded from very low to low, as the risk of bias was rated as 'not serious' in this case. In the case of Caesarean section, the association was downgraded from suggestive (class III) to non-significant, and the GRADE certainty was downgraded from low to very low. In the remaining cases, the GRADE certainty did not change between the main and the sensitivity analysis (Supplementary Table 3). This sensitivity was not performed for two risk factors: in the case of anaemia during pregnancy, all included studies were cohort, and for the 5-HTTLPR, none of the studies investigated cohorts.

In studies with standardised criteria for the PPD diagnosis/ symptoms, the association with PPD was upgraded from suggestive to highly suggestive for GDM, remained suggestive for Caesarean section, and was non-significant for labour epidural analgesia and medically assisted conception. The associations with PMS and unintended pregnancy were downgraded from highly suggestive to weak, violent experiences was downgraded from highly suggestive to suggestive, 5-HTTLPR polymorphism was downgraded from suggestive to weak, and preterm delivery and postpartum anaemia were downgraded from weak to non-significant. The GRADE certainty was upgraded only for anaemia and PMS, from very low to low, whereas the association with 5-HTTLPR polymorphism remained low. In all other cases, GRADE certainty was very low, as in the main analysis (Supplementary Table 4). For anaemia during pregnancy and vitamin $\mathrm{D}$ deficiency, sensitivity analysis was not performed, as not enough studies using standardised criteria were available (one and zero studies, respectively).

Excluding studies that assessed mood symptoms within the first postpartum week, the strength of association remained for violent experiences, Caesarean section, vitamin D deficiency, preterm 
Table 1 AMSTAR-2 assessment of the included meta-analyses

\begin{tabular}{|c|c|c|c|c|c|c|c|c|c|c|c|c|}
\hline & AMSTAR-2 questions & $\begin{array}{l}\text { PMS (Cao } \\
\text { et al, } \\
2020)^{59}\end{array}$ & $\begin{array}{l}\text { Experience of } \\
\text { violence } \\
\text { (Zhang et al, }_{2019)^{17}}\end{array}$ & $\begin{array}{l}\text { Unintended } \\
\text { pregnancy } \\
\text { (Qiu et al, } \\
2020)^{63}\end{array}$ & $\begin{array}{l}\text { 5-HTTLPR } \\
\text { polymorphism (Li } \\
\text { et al, 2020) }\end{array}$ & $\begin{array}{l}\text { Caesarean } \\
\text { section } \\
(\text { Xu et al, } \\
2017)^{26}\end{array}$ & $\begin{array}{l}\text { Gestational } \\
\text { diabetes } \\
\text { (Azami et al, }_{2019)^{62}}\end{array}$ & $\begin{array}{l}\text { Preterm } \\
\text { (De Paula } \\
\text { Eduardo } \\
\text { et al, } \\
\text { 2019) }\end{array}$ & $\begin{array}{l}\text { Anaemia } \\
\text { (Azami } \\
\text { et al, } \\
2019)^{61}\end{array}$ & $\begin{array}{l}\text { Vitamin D } \\
\text { deficiency } \\
\text { (Wang et al, }_{2018)^{21}}\end{array}$ & $\begin{array}{l}\text { Medically } \\
\text { assisted } \\
\text { conception } \\
\text { (Gressier et al, } \\
\text { 2015) }\end{array}$ & $\begin{array}{l}\text { Labour epidural } \\
\text { analgesia } \\
\text { (Kountanis et al, }_{2020)^{27}}\end{array}$ \\
\hline 1 & $\begin{array}{l}\text { Did the research questions and } \\
\text { inclusion criteria for the review } \\
\text { include the components of } \\
\text { PICO? }\end{array}$ & Yes & Yes & Yes & Yes & Yes & Yes & Yes & Yes & Yes & Yes & Yes \\
\hline 2 & $\begin{array}{l}\text { Did the report of the review } \\
\text { contain an explicit } \\
\text { statement that the review } \\
\text { methods were established } \\
\text { before the conduct of the } \\
\text { review and did the report } \\
\text { justify any significant } \\
\text { deviations from the } \\
\text { protocol? }\end{array}$ & No & No & No & No & No & No & No & Yes & No & No & Yes \\
\hline 3 & $\begin{array}{l}\text { Did the review authors explain } \\
\text { their selection of the study } \\
\text { designs for inclusion in the } \\
\text { review? }\end{array}$ & No & Yes & Yes & No & Yes & No & Yes & No & No & No & No \\
\hline 4 & $\begin{array}{l}\text { Did the review authors use a } \\
\text { comprehensive literature } \\
\text { search strategy? }\end{array}$ & Yes & Yes & Yes & Yes & Yes & Yes & Yes & Yes & Yes & Yes & Yes \\
\hline 5 & $\begin{array}{l}\text { Did the review authors perform } \\
\text { study selection in duplicate? }\end{array}$ & No & No & No & Yes & Yes & Yes & Yes & Yes & Yes & Yes & Yes \\
\hline 6 & $\begin{array}{l}\text { Did the review authors perform } \\
\text { data extraction in duplicate? }\end{array}$ & Yes & Yes & Yes & Yes & Yes & Yes & No & Yes & Yes & No & Yes \\
\hline 7 & $\begin{array}{l}\text { Did the review authors provide } \\
\text { a list of excluded studies } \\
\text { and justify the exclusions? }\end{array}$ & Yes & No & No & No & No & No & No & No & No & Yes & No \\
\hline 8 & $\begin{array}{l}\text { Did the review authors describe } \\
\text { the included studies in } \\
\text { adequate detail? }\end{array}$ & Yes & Yes & Yes & No & Yes & Yes & No & Yes & Yes & Yes & No \\
\hline 9 & $\begin{array}{l}\text { Did the review authors use a } \\
\text { satisfactory technique for } \\
\text { assessing the risk of bias in } \\
\text { individual studies that were } \\
\text { included in the review? }\end{array}$ & Yes & Yes & Yes & Yes & Yes & Yes & Yes & Yes & Yes & Yes & Yes \\
\hline 10 & $\begin{array}{l}\text { Did the review authors report on } \\
\text { the sources of funding for the } \\
\text { studies included in the review? }\end{array}$ & No & No & No & No & No & No & No & No & No & No & No \\
\hline 11 & $\begin{array}{l}\text { If meta-analysis was } \\
\text { performed did the review } \\
\text { authors use appropriate } \\
\text { methods for statistical } \\
\text { combination of results? }\end{array}$ & Yes & Yes & Yes & Yes & Yes & Yes & Yes & No & Yes & Yes & Yes \\
\hline
\end{tabular}




\begin{tabular}{|c|c|c|c|c|c|c|c|c|c|c|c|c|}
\hline & AMSTAR-2 questions & $\begin{array}{l}\text { PMS (Cao } \\
\text { et al, } \\
2020)^{59}\end{array}$ & $\begin{array}{l}\text { Experience of } \\
\text { violence } \\
\text { (Zhang et al, } \\
2019)^{17}\end{array}$ & $\begin{array}{l}\text { Unintended } \\
\text { pregnancy } \\
\text { (Qiu et al, } \\
2020)^{63}\end{array}$ & $\begin{array}{l}\text { 5-HTTLPR } \\
\text { polymorphism (Li } \\
\text { et al, 2020) }\end{array}$ & $\begin{array}{l}\text { Caesarean } \\
\text { section } \\
(\text { Xu et al, } \\
2017)^{26}\end{array}$ & $\begin{array}{l}\text { Gestational } \\
\text { diabetes } \\
\text { (Azami et al, }_{2019)^{62}}\end{array}$ & $\begin{array}{l}\text { Preterm } \\
\text { (De Paula } \\
\text { Eduardo } \\
\text { et al, } \\
\text { 2019) }\end{array}$ & $\begin{array}{l}\text { Anaemia } \\
\text { (Azami } \\
\text { et al, } \\
\text { 2019) }\end{array}$ & $\begin{array}{l}\text { Vitamin D } \\
\text { deficiency } \\
\text { (Wang et al, } \\
\text { 2018) }\end{array}$ & $\begin{array}{l}\text { Medically } \\
\text { assisted } \\
\text { conception } \\
\text { (Gressier et al, } \\
2015)^{60}\end{array}$ & $\begin{array}{l}\text { Labour epidural } \\
\text { analgesia } \\
\text { (Kountanis et al, }_{2020)^{27}}\end{array}$ \\
\hline 12 & $\begin{array}{l}\text { If meta-analysis was performed, } \\
\text { did the review authors assess } \\
\text { the potential impact of risk of } \\
\text { bias in individual studies on the } \\
\text { results of the meta-analysis or } \\
\text { other evidence synthesis? }\end{array}$ & Yes & Yes & Yes & No & Yes & No & No & No & Yes & Yes & No \\
\hline 13 & $\begin{array}{l}\text { Did the review authors } \\
\text { account for risk of bias in } \\
\text { individual studies when } \\
\text { interpreting/ discussing the } \\
\text { results of the review? }\end{array}$ & Yes & Yes & Yes & No & Yes & No & No & Yes & Yes & Yes & Yes \\
\hline 14 & $\begin{array}{l}\text { Did the review authors provide a } \\
\text { satisfactory explanation for, } \\
\text { and discussion of, any } \\
\text { heterogeneity observed in the } \\
\text { results of the review? }\end{array}$ & Yes & Yes & Yes & Yes & Yes & Yes & Yes & Yes & Yes & Yes & No \\
\hline 15 & $\begin{array}{l}\text { If they performed quantitative } \\
\text { synthesis did the review } \\
\text { authors carry out an } \\
\text { adequate investigation of } \\
\text { publication bias (small } \\
\text { study bias) and discuss its } \\
\text { likely impact on the results } \\
\text { of the review? }\end{array}$ & Yes & Yes & Yes & Yes & Yes & Yes & No & Yes & Yes & Yes & No \\
\hline 16 & $\begin{array}{l}\text { Did the review authors report any } \\
\text { potential sources of conflict of } \\
\text { interest, including any funding } \\
\text { they received for conducting } \\
\text { the review? }\end{array}$ & Yes & Yes & Yes & Yes & Yes & No & Yes & No & Yes & Yes & No \\
\hline Nur & mber of critical weaknesses & 1 & 2 & 2 & 3 & 3 & 3 & 3 & 2 & 2 & 1 & 2 \\
\hline Nur & mber of non-critical weaknesses & 3 & 2 & 2 & 4 & 1 & 4 & 4 & 4 & 2 & 3 & 6 \\
\hline & $\begin{array}{l}\text { oorting quality of each meta- } \\
\text { analysis }\end{array}$ & Moderate & Critically low & Critically low & Critically low & $\begin{array}{l}\text { Critically } \\
\text { low }\end{array}$ & Critically low & $\begin{array}{l}\text { Critically } \\
\text { low }\end{array}$ & $\begin{array}{l}\text { Critically } \\
\text { low }\end{array}$ & $\begin{array}{l}\text { Critically } \\
\text { low }\end{array}$ & Low & Critically low \\
\hline
\end{tabular}




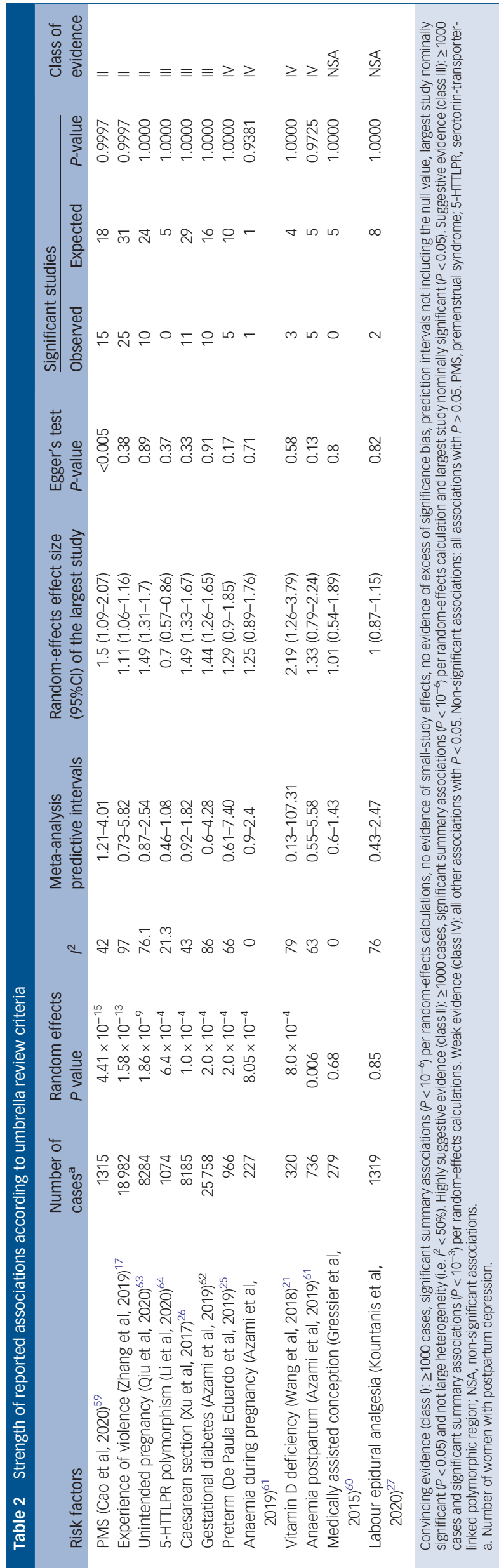

delivery and unintended pregnancy, whereas the association with GDM was downgraded by one level and the association with PMS and 5-HTTLPR polymorphism was downgraded by two levels. For the latter, we no longer found a significant association (Supplementary Table 5). Intra-labour epidural analgesia and medically assisted conception remained non-significant. For both types of anaemia, it was not possible to perform analyses, as study evaluations occurred after the first postpartum week. No differences between the main and sensitivity analysis were found in GRADE, except for the 5HTTLPR polymorphism, which was downgraded from low to very low (Supplementary Table 5).

\section{Discussion}

The most reliable association with PPD was found for women suffering from PMS, followed by violent experiences and unintended pregnancy. The risk of PPD was more than doubled in women with PMS or a violent experience, and was 50\% higher in women with unintended pregnancy. Women suffering from PMS could have an affective vulnerability underpinned by hormonal fluctuations, which occur both during the premenstrual period and on a much larger scale during postpartum. ${ }^{65}$ Experience of violence may be a less specific risk factor, as it has been implicated in different psychiatric disorders, including other affective and addiction disorders. ${ }^{66,67}$ Unintended pregnancy has been previously suggested as a PPD risk factor, mainly because of increased stress levels, which can activate the hypothalamic-pituitary-adrenal axis, resulting in a release of glucocorticoids influencing psychological functions. ${ }^{68,69}$ Specifically, women who did not plan their pregnancy may be unprepared/worried about the health of the foetus, feel a potential conflict between continuing and terminating the pregnancy, and start the prenatal care later than women who planned the pregnancy. ${ }^{70-72}$

For these risk factors, the effect sizes were generally small (odds ratio <3.5), ${ }^{73}$ despite the URC showing class II associations. Therefore, evidence regarding such associations might only play a partial role with respect to depression onset, and confounding could not be ruled out because of the observational nature of studies, which was reflected by the GRADE certainty (very low).

At an intermediate credibility level, we found associations of PPD with 5-HTTLPR polymorphism, Caesarean section and GDM. The latter increased the risk of PPD by $60 \%$. Conversely, women who underwent Caesarean section had a slightly increased risk of PPD. However, it is noteworthy that in the included metaanalysis, ${ }^{26}$ Caesarean section was a significant risk factor for PPD when performed in an emergency situation, but not when elective, suggesting a central role of unexpected complications for PPD. The allelic model of 5-HTTLPR polymorphism was the only protective factor, which slightly reduced the PPD risk. The 5-HTT gene is a key factor that affects risk for depression and other mental disorders. ${ }^{74}$ The transcriptional activity of the 5-HTT gene may be regulated by this polymorphism, ${ }^{75,76}$ resulting in different levels of serotonin transporters, increasing the susceptibility to affective disorders. ${ }^{77,78}$

Sensitivity analyses in cohort studies confirmed all of the results, with the exception of the association between PPD and PMS, which was found to be less reliable, dropping from highly suggestive to weak because of the small number of cases.

The sensitivity analyses based on standardised criteria for PPD led to different results. Here, we discuss the most relevant differences. First, it is important to note that the evidence on GDM was upgraded to highly suggestive with a slightly higher odds ratio (from 1.44 to 1.57), indicating that GDM may be more strongly associated with clinical depression rather than subclinical depressive symptoms. Second, evidence on PMS, unintended pregnancy and 5-HTTLPR 


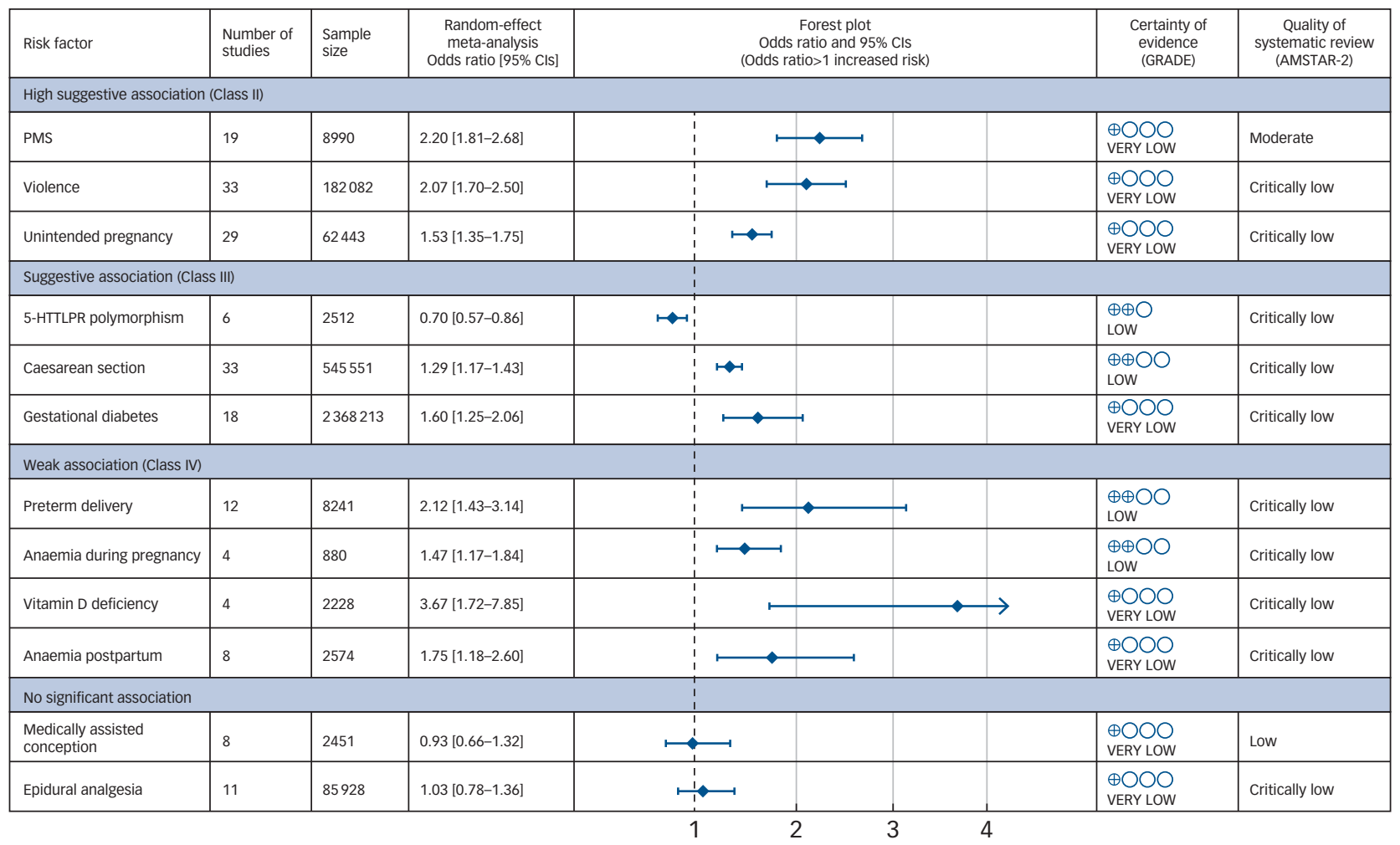

Fig. 2 Ranking of associations on the risk of post-partum depression with exposure to risk factors.

5-HTTLPR, serotonin-transporter-linked polymorphic region; AMSTAR-2, A Measurement Tool to Assess Systematic Reviews; GRADE, Grading of Recommendations, Assessment, Development and Evaluations; PMS, premenstrual syndrome.

polymorphism was downgraded to weak, suggesting that these factors might be associated with subclinical depression symptoms.

Restricting the analyses to studies with an assessment after the first postpartum week, we found lower certainty for almost all associations, with the exception of the association of PPD with violent experiences, Caesarean section and unintended pregnancy. These associations remained at the same level of credibility indicating that apart from violent experiences, Caesarean section and unintended pregnancy, the other risk (or protective) factors might be associated more with the so-called 'maternity blues' or adjustments within the first postpartum week, rather than with depression diagnosed later. This result is notable if we consider that authors previously suggested that maternity blues could be a risk factor for developing depression later on in the postpartum period. ${ }^{13,79,80}$

Moreover, the credibility of the association with violent experiences was maintained across all analyses. The increased risk was slightly lower in the two sensitivity analyses based on clinical criteria and assessment timing, suggesting that some bias could have inflated the main results. Nevertheless, violent experiences were found as one of the most reliable risk factors for developing PPD, in line also with literature on major depression. ${ }^{66}$

Finally, the sensitivity analyses confirmed the non-differential results on medically assisted conception and intra-labour epidural analgesia, which neither increased nor decreased the risk of PPD, suggesting that the influence of these factors might be negligible. Some authors suggested that the quality of the intra-labour analgesia might be related with women's satisfaction, and therefore with reduced stress during delivery, becoming a possible protective factor for PPD. ${ }^{81}$ Further studies with less confounders are needed to confirm these hypotheses.

The American College of Obstetricians and Gynecologists recommends that obstetrician-gynaecologists and other obstetric care providers screen patients at least once during the perinatal period for depression and anxiety symptoms, using a standardised, validated tool. ${ }^{82}$ We suggest that, based on the results of this umbrella review, the risk factors listed in this tool might need to be revised and updated along with guidelines. Specifically, considering that currently PMS, Caesarean section and GDM are not included in the tool, we suggest that these risk factors may be at least considered. Moreover, the assessment of some risk factors, such as violent experience, that are only partially mentioned under the 'Experiencing stressful life events' category, could be more weighted. Finally, some risk factors already considered may be less strong than commonly considered, such as preterm delivery.

A number of limitations need to be considered when interpreting these results. First, although broadly employed in mental health and medicine, ${ }^{50,51,53-55,66}$ and corroborated by standard statistical tests, ${ }^{42,44-46}$ the URC classification to classify strengths has been just recently introduced. The criteria of the $\geq 1000$ cases might not be fully applicable for studies that target very specific samples, especially those with low incidence.

A second general cautionary note is the observational nature of the primary studies, which does not allow us to establish a causal association between risk factors and PPD. Moreover, this type of studies is vulnerable to bias because of unmeasured confounding and lower internal validity compared with randomised controlled trials. ${ }^{83,84}$ In fact, it is unclear if some of the investigated factors were proxies for other factors or shared background risk. It should be noted, however, that this risk of bias is taken into consideration by GRADE, which suggests rating the certainty of estimates from observational studies as low quality instead of high quality, to acknowledge issues with internal validity. ${ }^{56}$ On the other hand, findings of meta-analyses of observational studies are more generalisable and pragmatic, as they have larger sample 


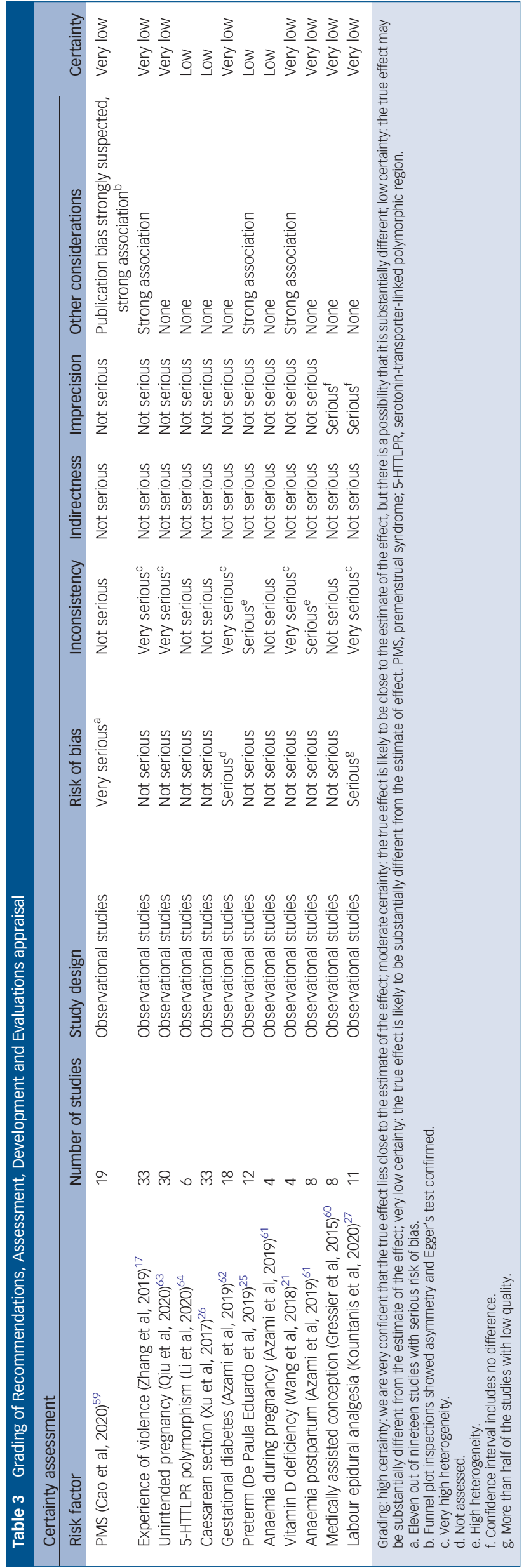

sizes and include real-world patients. ${ }^{85,86}$ Moreover, although qualitatively more reliable, a randomised design is not the best design to address risk factors.

Third, the investigated populations were highly heterogeneous, also because of the variations in the definitions of assessed risk factors. Despite attempts to adjust for relevant variables, heterogeneity lowered the reliability of the identified associations. As previously argued, genuine heterogeneity might operate in the field of depression research for several cultural reasons. ${ }^{66}$ Future observational studies should attempt to better identify high-risk groups by adopting sophisticated measures of exposure to risk factors. On a secondary level, future meta-analyses should access individual-level patient data and apply harmonised inclusion criteria, covariate definitions and statistical approaches. ${ }^{87}$

Fourth, none of the risk factors for PPD were supported by convincing evidence. This may be because of specific limitations in this research field. Pregnant women are a very specific and limited population, and PPD has a lower prevalence in the general population compared with other mental disorders. Moreover, the field of perinatal mental and physical health research faces several obstacles that traditionally relate to ethical challenges of conducting research in these vulnerable populations, as well as to the involvement of various disciplines, which requires multidisciplinary approaches. ${ }^{88,89}$ This fact may further explain the lower number of women enrolled in studies in the peripartum period compared with depression unrelated to pregnancy and childbirth or other disorders. ${ }^{90}$ Hence, it is expected that the number of cases evaluated could be low $(<1000)$, which is the first URC criterion to upgrade the class of evidence. ${ }^{28,30}$

Finally, data for some potential or known risk factors for PPD may not have been meta-analysed yet, and thus were not included in our umbrella review, such as social support of the mother, history of mental disorders, income, maternity blues and obesity. ${ }^{91}$ This limitation refers to the umbrella review methodology, as this approach is based on a statistical re-analysis of meta-analyses. Therefore, umbrella reviews only include statistical re-analyses with a meta-analysis (i.e. that employed a quantitative approach to the data presentation), whereas statistical re-analyses providing only qualitative descriptions of the included studies are excluded. However, typically the lack of a meta-analytical approach is driven by lack of sufficient and homogeneous data. ${ }^{30}$

Despite these limitations, the main strengths of this work are still the comprehensiveness of the search and the quantitative and qualitative approaches employed to rate the credibility of evidence. To the best of our knowledge, this is the first umbrella review that systematically summarised data on the association between PPD and several risk and protective factors grading the certainty and strength of evidence by applying well-recognised criteria. ${ }^{2,30,55}$ A previous overview of reviews on PPD risk factors was recently published; however, the authors did not perform any re-analysis and did not grade the credibility of evidence and strength of association by using any qualitative or quantitative criteria. ${ }^{13}$ In contrast with our approach, Hutchens and Kearney ${ }^{13}$ narratively summarised systematic reviews on PPD risk factor, regardless of the presence of a meta-analysis. Moreover, previous umbrella reviews have assessed risk factors for other mental disorders, such as depression, anxiety and psychosis, but did not include PPD or postpartum depressive symptoms. ${ }^{48,54,66,92-94}$ Our approach led to the inclusion of an extremely large number of participants, at over 3 million. Additionally, the retrieved risk factors were either social/ environmental stressors or medical/obstetric complications of the pregnancy and delivery. This highlights the central role of social environment in the future mothers' mental health and well-being, as well as in the pathogenesis of mental disorders in the general population. ${ }^{13,95,96}$ 
Furthermore, this work provides methodological directions for future studies aiming to improve our understanding of predictors of PPD. First, there is an urgent need to generate further multidisciplinary evidence to more effectively tackle mental (and physical) health challenges for women during pregnancy, as well as the postpartum phase. ${ }^{90,97}$ Second, further replication of the evidence regarding biological and psychosocial factors in more sophisticated models is hoped to lay the groundwork for a comprehensive PPD screening tool. Moreover, timing of assessment of depression seems extremely relevant. Therefore, more well-designed, prospective observational studies on risk factors for PPD, collecting data pre/ intrapartum and following up on women after the first week postpartum are needed to determine whether risk factors are associated with maternity blues or later depression..$^{95,98}$ Ultimately, our data may enhance efforts to develop interdisciplinary prevention and care targeting patients at high risk for PPD.

Our results could be of help in updating postpartum screening tools employed to identify and screen women at risk of PPD, such as the one developed by the American College of Obstetricians and Gynecologists. ${ }^{82}$ The early recognition and management of these patients will improve treatment outcomes improving maternal health and new-born development.

Chiara Gastaldon (D), WHO Collaborating Centre for Research and Training in Menta Health and Service Evaluation, Department of Neuroscience, Biomedicine and Movement Sciences, Section of Psychiatry, University of Verona, Italy; and Department of Psychiatry, The Zucker Hillside Hospital, Northwell Health, New York, USA; Marco Solmi, Department of Neuroscience, University of Padua, Italy; and Padua Neuroscience Center University of Padua, Italy; Christoph U. Correll, Department of Psychiatry, The Zucker Hillside Hospital, Northwell Health, New York, USA; Department of Psychiatry and Molecular Medicine The Donald and Barbara Zucker School of Medicine at Hofstra/ Northwell, New York, USA; Center for Psychiatric Neuroscience, The Feinstein Institute for Medical Research, New York, USA; and Department of Child and Adolescent Psychiatry, Charité Universitätsmedizin, Germany; Corrado Barbui (D), WHO collaborating Centre for Research and Training in Mental Health and Service Evaluation Department of Neuroscience, Biomedicine and Movement Sciences, Section of Psychiatry, University of Verona, Italy; Georgios Schoretsanitis (ID), Department of Psychiatry, The Zucker Hillside Hospital, Northwell Health, New York, USA; and Department of Psychiatry, Psychotherapy and Psychosomatics, Psychiatric Hospital, University of Zurich, Switzerland

Correspondence: Chiara Gastaldon. Email: chiara.gastaldon@gmail.com

First received 21 May 2021, final revision 3 Dec 2021, accepted 17 Dec 202

\section{Supplementary material}

To view supplementary material for this article, please visit https://doi.org/10.1192/bjp.2021.222

\section{Data availability}

The data that support the findings of this study are available from the corresponding author, C.G., upon request.

\section{Author contributions}

C.G., G.S., C.B., M.S. and C.U.C. designed the study. C.G. and G.S. drafted the manuscript. C.G., G.S. and C.B. contributed to the database preparation and double-checked the data. C.G., G.S. and M.S. conducted data analyses. C.G. and G.S. assessed the quality of meta-analyses with AMSTAR-2. All authors critically revised the manuscript and approved the draft and final manuscripts.

\section{Funding}

This research received no specific grant from any funding agency, commercial or not-for-profit sectors.

\section{Declaration of interest}

C.B. and C.G. have nothing to disclose. G.S. has served as a consultant for HLS Therapeutics. C.U.C. has been a consultant and/or advisor to, or has received honoraria from, Alkermes,
Allergan, Angelini, Boehringer-Ingelheim, Gedeon Richter, Gerson Lehrman Group, Indivior, IntraCellular Therapies, Janssen/I\&, L B Pharma, Lundbeck, MedAvante ProPhase, MedinCell,

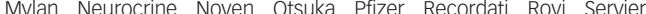
Sumitomo Dainippon, Sunovion, Supernus, Takeda and Teva. He has provided expert testimony for Bristol-Myers Squibb, Janssen and Otsuka. He served on a Data Safety Monitoring Board for Boehringer-Ingelheim, Lundbeck, Rovi, Supernus and Teva. He has received royalties from UpToDate and grant support from Janssen and Takeda. He is also a shareholder of LB Pharma. M.S. has been a consultant and/or advisor to, or has received honoraria, from Angelini and Lundbeck.

\section{References}

1 Gelaye B, Rondon MB, Araya R, Williams MA. Epidemiology of maternal depression, risk factors, and child outcomes in low-income and middleincome countries. Lancet Psychiatry 2016; 3(10): 973-82.

2 American Psychiatric Association. Diagnostic and Statistical Manual of Mental Disorders (5th edn). American Psychiatric Association, 2013.

3 Fonseca A, Ganho-Avila A, Lambregtse-van den Berg M, Lupattelli A, Rodriguez-Munoz MF, Ferreira $P$, et al. Emerging issues and questions on peripartum depression prevention, diagnosis and treatment: a consensus report from the COST action RISEUP-PPD. J Affect Disord 2020; 274: 167-73.

4 Putnam KT, Wilcox M, Robertson-Blackmore E, Sharkey K, Bergink V, MunkOlsen $\mathrm{T}$, et al. Clinical phenotypes of perinatal depression and time of symptom onset: analysis of data from an international consortium. Lancet Psychiatry 2017; 4(6): 477-85.

5 World Health Organization. International Statistical Classification of Diseases and Related Health Problems (10th edn). World Health Organization, 1992.

6 Postpartum Depression: Action Towards Causes and Treatment (PACT) Consortium. Heterogeneity of postpartum depression: a latent class analysis. Lancet Psychiatry 2015; 2(1): 59-67.

7 Srinivasan R, Pearson RM, Johnson S, Lewis G, Lewis G. Maternal perinatal depressive symptoms and offspring psychotic experiences at 18 years of age: a longitudinal study. Lancet Psychiatry 2020; 7(5): 431-40.

8 Kamau C. Postpartum depression or psychosis and return to work. Lancet Psychiatry 2017; 4(2): 96-7.

9 Netsi E, Pearson RM, Murray L, Cooper P, Craske MG, Stein A. Association of persistent and severe postnatal depression with child outcomes. JAMA Psychiatry 2018; 75(3): 247-53.

10 Duan Z, Wang Y, Tao Y, Bower JL, Yu R, Wang S, et al. Relationship between trait neuroticism and suicidal ideation among postpartum women in China: testing a mediation model. J Affect Disord 2019; 256: 532-5.

11 O'Connor E, Rossom RC, Henninger M, Groom HC, Burda BU. Primary care screening for and treatment of depression in pregnant and postpartum women: evidence report and systematic review for the US preventive services task force. JAMA 2016; 315(4): 388-406

12 Kuehn BM. Postpartum depression screening needs more consistency. JAMA 2020; 323(24): 2454.

13 Hutchens BF, Kearney J. Risk factors for postpartum depression: an umbrella review. J Midwifery Womens Health 2020; 65(1): 96-108.

14 Frieden TR. Evidence for health decision making - beyond randomized, controlled trials. N Engl J Med 2017; 377(5): 465-75.

15 Beck CT. A meta-analysis of predictors of postpartum depression. Nurs Res 1996; 45(5): 297-303

16 Alvarez-Segura M, Garcia-Esteve L, Torres A, Plaza A, Imaz ML, Hermida-Barros $\mathrm{L}$, et al. Are women with a history of abuse more vulnerable to perinatal depressive symptoms? A systematic review. Arch Womens Ment Health 2014; 17(5): 343-57.

17 Zhang S, Wang L, Yang T, Chen L, Qiu X, Wang T, et al. Maternal violence experiences and risk of postpartum depression: a meta-analysis of cohort studies. Eur Psychiatry 2019; 55: 90-101.

18 Dibaba $Y$, Fantahun M, Hindin MJ. The association of unwanted pregnancy and social support with depressive symptoms in pregnancy: evidence from rural Southwestern Ethiopia. BMC Pregnancy Childbirth 2013; 13: 135

19 Azad R, Fahmi R, Shrestha S, Joshi H, Hasan M, Khan ANS, et al. Prevalence and risk factors of postpartum depression within one year after birth in urban slums of Dhaka, Bangladesh. PLOS One 2019; 14(5): e0215735.

20 Nakamura A, van der Waerden J, Melchior M, Bolze C, El-Khoury F, Pryor L. Physical activity during pregnancy and postpartum depression: systematic review and meta-analysis. J Affect Disord 2019; 246: 29-41.

21 Wang J, Liu N, Sun W, Chen D, Zhao J, Zhang W. Association between vitamin D deficiency and antepartum and postpartum depression: a systematic review and meta-analysis of longitudinal studies. Arch Gynecol Obstet 2018; 298(6): 1045-59. 
22 Kang SY, Kim HB, Sunwoo S. Association between anemia and materna depression: a systematic review and meta-analysis. J Psychiatr Res 2020; 122 88-96.

23 Caropreso L, de Azevedo Cardoso T, Eltayebani M, Frey BN. Preeclampsia as a risk factor for postpartum depression and psychosis: a systematic review and meta-analysis. Arch Womens Ment Health 2020; 23(4): 493-505.

24 Teo C, Chia AR, Colega MT, Chen LW, Fok D, Pang WW, et al. Prospective associations of maternal dietary patterns and postpartum mental health in a multi-ethnic Asian cohort: the growing up in Singapore Towards Healthy Outcomes (GUSTO) study. Nutrients 2018; 10(3): 299.

25 de Paula Eduardo JAF, de Rezende MG, Menezes PR, Del-Ben CM. Preterm birth as a risk factor for postpartum depression: a systematic review and metaanalysis. J Affect Disord 2019; 259: 392-403.

$26 \mathrm{Xu} \mathrm{H}$, Ding Y, Ma Y, Xin X, Zhang D. Cesarean section and risk of postpartum depression: a meta-analysis. J Psychosom Res 2017; 97: 118-26.

27 Kountanis J, Vahabzadeh C, Bauer S, Muzik M, Cassidy R, Aman C, et al. Labor epidural analgesia and the risk of postpartum depression: a meta-analysis of observational studies. J Clin Anesth 2020; 61: 109658.

28 Solmi M, Correll CU, Carvalho AF, Ioannidis JPA. The role of meta-analyses and umbrella reviews in assessing the harms of psychotropic medications: beyond qualitative synthesis. Epidemiol Psychiatr Sci 2018; 27(6): 537-42.

29 Stroup DF, Berlin JA, Morton SC, Olkin I, Williamson GD, Rennie D, et al. Metaanalysis of observational studies in epidemiology: a proposal for reporting. Meta-analysis of Observational Studies in Epidemiology (MOOSE) group. JAMA 2000; 283(15): 2008-12

30 Fusar-Poli $\mathrm{P}$, Radua J. Ten simple rules for conducting umbrella reviews. Evid Based Ment Health 2018; 21(3): 95-100.

31 Aromataris E, Fernandez R, Godfrey CM, Holly C, Khalil H, Tungpunkom P. Summarizing systematic reviews: methodological development, conduct and reporting of an umbrella review approach. Int J Evid Based Healthc 2015; 13(3): 132-40.

32 Ioannidis JP. Integration of evidence from multiple meta-analyses: a primer on umbrella reviews, treatment networks and multiple treatments meta-analyses. CMAJ 2009; 181(8): 488-93.

33 Grant MJ, Booth A. A typology of reviews: an analysis of 14 review types and associated methodologies. Health Info Libr J 2009; 26(2): 91-108.

34 Fusar-Poli P, Hijazi Z, Stahl D, Steyerberg EW. The science of prognosis in psychiatry: a review. JAMA Psychiatry 2018; 75(12): 1289-97.

35 Radua J, Ramella-Cravaro V, Ioannidis JPA, Reichenberg A, Phiphopthatsane $\mathrm{N}$, Amir $\mathrm{T}$, et al. What causes psychosis? An umbrella review of risk and protective factors. World Psychiatry 2018; 17(1): 49-66.

36 Raglan O, Kalliala I, Markozannes G, Cividini S, Gunter MJ, Nautiyal J, et al. Risk factors for endometrial cancer: an umbrella review of the literature. Int J Cancer 2019; 145: 1719-30.

37 Theodoratou E, Tzoulaki I, Zgaga L, Ioannidis JP. Vitamin D and multiple health outcomes: umbrella review of systematic reviews and meta-analyses of observational studies and randomised trials. BMJ 2014; 348: g2035.

38 Shea BJ, Reeves BC, Wells G, Thuku M, Hamel C, Moran J, et al. AMSTAR 2: a critical appraisal tool for systematic reviews that include randomised or non-randomised studies of healthcare interventions, or both. BMJ 2017; 358 j4008.

39 AMSTAR. A MeaSurement Tool to Assess systematic Reviews: AMSTAR-2 Checklist. AMSTAR, No date (https://amstar.ca/Amstar_Checklist.php [cited March 2020]).

40 DerSimonian R, Laird N. Meta-analysis in clinical trials. Control Clin Trials 1986 7(3): 177-88

41 Riley RD, Higgins JP, Deeks JJ. Interpretation of random effects meta-analyses. BMJ 2011; 342: d549.

42 Cochran WG. The combination of estimates from different experiments. Biometrics 1954; 10(1): 101-29.

43 Higgins JP, Thompson SG, Deeks JJ, Altman DG. Measuring inconsistency in meta-analyses. BMJ 2003; 327(7414): 557-60.

44 Sterne JA, Sutton AJ, Ioannidis JP, Terrin N, Jones DR, Lau J, et al. Recommendations for examining and interpreting funnel plot asymmetry in meta-analyses of randomised controlled trials. BMJ 2011; 343: d4002.

45 Egger M, Smith GD, Schneider M, Minder C. Bias in meta-analysis detected by a simple, graphical test. BMJ 1997; 315(7109): 629-34.

46 Ioannidis JP, Trikalinos TA. An exploratory test for an excess of significant findings. Clin Trials 2007; 4(3): 245-53.

47 Lubin JH, Gail MH. On power and sample size for studying features of the relative odds of disease. Am J Epidemiol 1990; 131(3): 552-66.

48 Bortolato B, Köhler CA, Evangelou E, León-Caballero J, Solmi M, Stubbs B, et al. Systematic assessment of environmental risk factors for bipolar disorder: an umbrella review of systematic reviews and meta-analyses. Bipolar Disord 2017: 19(2): 84-96.

49 Dragioti E, Evangelou E، Larsson B, Gerdle B. Effectiveness of multidisciplinary programmes for clinical pain conditions: an umbrella review. J Rehabil Med 2018; 50: 779-91.

50 Bellou V, Belbasis L, Tzoulaki I, Evangelou E, Ioannidis JP. Environmental risk factors and Parkinson's disease: an umbrella review of meta-analyses. Parkinsonism Relat Disord 2016; 23: 1-9.

51 Tsilidis KK, Kasimis JC, Lopez DS, Ntzani EE, Ioannidis JPA. Type 2 diabetes and cancer: umbrella review of meta-analyses of observational studies. BMJ 2015; 350: g7607.

52 Dragioti E, Karathanos V, Gerdle B, Evangelou E. Does psychotherapy work? An umbrella review of meta-analyses of randomized controlled trials. Acta Psychiatr Scand 2017; 136(3): 236-46.

53 Papola D, Ostuzzi G, Thabane L, Guyatt G, Barbui C. Antipsychotic drug exposure and risk of fracture: a systematic review and metaanalysis of observational studies. Int Clin Psychopharmacol 2018; 33(4): $181-96$.

54 Machado MO, Veronese N, Sanches M, Stubbs B, Koyanagi A, Thompson T, et al. The association of depression and all-cause and cause-specific mortality: an umbrella review of systematic reviews and meta-analyses. BMC Med 2018; 16: 112

55 Barbui C, Purgato M, Abdulmalik J, Acarturk C, Eaton J, Gastaldon C, et al. Efficacy of psychosocial interventions for mental health outcomes in lowincome and middle-income countries: an umbrella review. Lancet Psychiatry 2020; 7(2): 162-72

56 Guyatt GH, Oxman AD, Vist GE, Kunz R, Falck-Ytter $Y$, Alonso-Coello $P$, et al. GRADE: an emerging consensus on rating quality of evidence and strength of recommendations. BMJ 2008; 336(7650): 924-6.

57 Guyatt GH, Thorlund K, Oxman AD, Walter SD, Patrick D, Furukawa TA, et al. GRADE guidelines: 13. Preparing summary of findings tables and evidence profiles-continuous outcomes. J Clin Epidemiol 2013; 66(2): 173-83.

58 Balshem $H$, Helfand $M$, Schünemann $H J$, Oxman AD, Kunz R, Brozek J, et al. GRADE guidelines: 3. Rating the quality of evidence. J Clin Epidemiol 2011; 64(4): 401-6

59 Cao S, Jones M, Tooth L, Mishra GD. History of premenstrual syndrome and development of postpartum depression: a systematic review and meta-analysis. J Psychiatr Res 2020; 121: 82-90.

60 Gressier F, Letranchant A, Cazas O, Sutter-Dallay AL, Falissard B, Hardy P. Postpartum depressive symptoms and medically assisted conception: a systematic review and meta-analysis. Hum Reprod 2015; 30(11): 2575-86.

61 Azami M, Badfar G, Khalighi Z, Qasemi P, Shohani M, Soleymani A, et al. The association between anemia and postpartum depression: a systematic review and meta-analysis. Caspian J Intern Med 2019; 10(2): 115-24.

62 Azami M, Badfar G, Soleymani A, Rahmati S. The association between gestational diabetes and postpartum depression: a systematic review and metaanalysis. Diabetes Res Clin Pract 2019; 149: 147-55.

63 Qiu X, Zhang S, Sun X, Li H, Wang D. Unintended pregnancy and postpartum depression: a meta-analysis of cohort and case-control studies. J Psychosom Res 2020; 138: 110259.

64 Li J, Chen Y, Xiang Q, Xiang J, Tang Y, Tang L. 5HTTLPR polymorphism and postpartum depression risk: a meta-analysis. Medicine (Baltimore) 2020; 99(39): e22319.

65 Amiel Castro RT, Pataky EA, Ehlert U. Associations between premenstrua syndrome and postpartum depression: a systematic literature review. Biol Psychol 2019; 147: 107612

66 Köhler CA, Evangelou E, Stubbs B, Solmi M, Veronese N, Belbasis L, et al. Mapping risk factors for depression across the lifespan: an umbrella review ovidence from meta-analyses and Mendelian randomization studies. J Psychiatr Res 2018; 103: 189-207.

67 Brown A, Cosgrave E, Killackey E, Purcell R, Buckby J, Yung AR. The longitudinal association of adolescent dating violence with psychiatric disorders and functioning. J Interpers Violence 2008; 24(12): 1964-79.

68 Brummelte S, Galea LAM. Depression during pregnancy and postpartum: contribution of stress and ovarian hormones. Prog Neuro-Psychopharmacol Biol Psychiatry 2010; 34(5): 766-76.

69 Meltzer-Brody S. New insights into perinatal depression: pathogenesis and treatment during pregnancy and postpartum. Dialogues Clin Neurosci 2011; 13(1): 89-100.

70 Karaçam Z, Onel K, Gercek E. Effects of unplanned pregnancy on maternal health in Turkey. Midwifery 2011; 27(2): 288-93.

71 Faisal-Cury A, Menezes PR, Quayle J, Matijasevich A. Unplanned pregnancy and risk of maternal depression: secondary data analysis from a prospective pregnancy cohort. Psychol Health Med 2017; 22(1): 65-74. 
72 Abbasi S, Chuang CH, Dagher R, Zhu J, Kjerulff K. Unintended pregnancy and postpartum depression among first-time mothers. J Womens Health 2013; 22(5): 412-6.

73 Chen $\mathrm{H}$, Cohen P, Chen S. How big is a big odds ratio? Interpreting the magnitudes of odds ratios in epidemiological studies. Commun Stat Simul Comput 2010; 39(4): 860-4.

74 Robson MJ, Quinlan MA, Blakely RD. Immune system activation and depression: roles of serotonin in the central nervous system and periphery. ACS Chem Neurosc 2017; 8(5): 932-42.

75 Hranilovic D, Stefulj J, Furac I, Kubat M, Balija M, Jernej B. Serotonin transporte gene promoter (5-HTTLPR) and intron 2 (VNTR) polymorphisms in Croatian suicide victims. Biol Psychiatry 2003; 54(9): 884-9.

76 Mushtaq R, Shoib S, Shah T, Mushtaq S. 5-Hydroxy tryptamine transporter $(5 \mathrm{HTT})$ gene promoter region polymorphism in anxiety and depressive disorders. Med J Islam Repub Iran 2014; 28: 127.

77 Ezaki N, Nakamura K, Sekine Y, Thanseem I, Anitha A, Iwata Y, et al. Short allele of 5-HTTLPR as a risk factor for the development of psychosis in Japanese methamphetamine abusers. Ann N Y Acad Sci 2008; 1139: 49-56.

78 Ming Q, Zhang Y, Yi J, Wang X, Zhu X, Yao S. Serotonin transporter gene polymorphism (5-HTTLPR) L allele interacts with stress to increase anxiety symptoms in Chinese adolescents: a multiwave longitudinal study. BMC Psychiatry 2015; 15: 248.

79 Beck CT. Predictors of postpartum depression: an update. Nurs Res 2001; 50(5): 275-85.

80 Bloch M, Rotenberg N, Koren D, Klein E. Risk factors for early postpartum depressive symptoms. Gen Hosp Psychiatry 2006; 28(1): 3-8.

81 Lim G, Farrell LM, Facco FL, Gold MS, Wasan AD. Labor analgesia as a predicto for reduced postpartum depression scores: a retrospective observational study. Anesth Analg 2018; 126(5): 1598-605.

82 ACOG Committee Opinion No. 757: screening for perinatal depression. Obstet Gynecol 2018; 132(5): e208-12.

83 Carlson MDA, Morrison RS. Study design, precision, and validity in observational studies. J Palliat Med 2009; 12(1): 77-82.

84 Schoretsanitis G, Deligiannidis KM. Prenatal complications and neurodevelopmental outcomes in offspring: interactions and confounders. Acta Psychiatr Scand 2020; 142(4): 261-3.

85 Song JW, Chung KC. Observational studies: cohort and case-control studies. Plast Reconstr Surg 2010; 126(6): 2234-42.

86 Barnish MS, Turner S. The value of pragmatic and observational studies in health care and public health. Pragmat Obs Res 2017; 8: 49-55.
87 Rubio JM, Schoretsanitis G, John M, Tiihonen J, Taipale H, Guinart D, et al. Psychosis relapse during treatment with long-acting injectable antipsychotics in individuals with schizophrenia-spectrum disorders: an individual participant data meta-analysis. Lancet Psychiatry 2020; 7(9): 749-61.

88 Committee on Ethics. ACOG Committee Opinion No. 646: ethical consideration for including women as research participants. Obstet Gynecol 2015; 126(5): e100-7.

89 Tachibana Y, Koizumi N, Akanuma C, Tarui H, Ishii E, Hoshina T, et al. Integrated mental health care in a multidisciplinary maternal and child health service in the community: the findings from the Suzaka trial. BMC Pregnancy Childbirth 2019; 19: 58.

90 Kaye DK. The moral imperative to approve pregnant women's participation in randomized clinical trials for pregnancy and newborn complications. Philos Ethics Humanit Med 2019; 14(1): 11.

91 Molyneaux E, Poston L, Ashurst-Williams S, Howard LM. Obesity and mental disorders during pregnancy and postpartum: a systematic review and metaanalysis. Obstet Gynecol 2014; 123(4): 857-67.

92 Solmi M, Radua J, Stubbs B, Ricca V, Moretti D, Busatta D, et al. Risk factors for eating disorders: an umbrella review of published meta-analyses. Braz J Psychiatry 2020; 43(3): 314-23.

93 Fullana MA, Tortella-Feliu M, Fernández de la Cruz L, Chamorro J, Pérez-Vigil A, oannidis JPA, et al. Risk and protective factors for anxiety and obsessivecompulsive disorders: an umbrella review of systematic reviews and metaanalyses. Psychol Med 2020; 50(8): 1300-15.

94 Belbasis L, Köhler CA, Stefanis N, Stubbs B, van Os J, Vieta E, et al. Risk factors and peripheral biomarkers for schizophrenia spectrum disorders: an umbrella review of meta-analyses. Acta Psychiatr Scand 2018; 137(2): 88-97.

95 Vasa R, Eldeirawi K, Kuriakose VG, Nair GJ, Newsom C, Bates J. Postpartum depression in mothers of infants in neonatal intensive care unit: risk factors and management strategies. Am J Perinatol 2014; 31(5): 425-34.

96 Campbell SB, Cohn JF, Flanagan C, Popper S, Meyers T. Course and correlates of postpartum depression during the transition to parenthood. Dev Psychopathol 1992; 4(1): 29-47.

97 Weld ED, Bailey TC, Waitt C. Ethical issues in therapeutic use and research in pregnant and breastfeeding women. Br J Clin Pharmacol [Epub ahead of print] 14 May 2021. Available from: https://doi.org/10.1111/bcp.14914.

98 Goodman JH. Postpartum depression beyond the early postpartum period. J Obstet Gynecol Neonatal Nurs 2004; 33(4): 410-20.

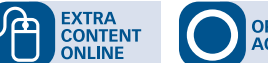

